\title{
Neurofibromatosis type 1 associated with pheochromocytoma
}

EP91

Slim T, Jemel M, Werdani S, Sayadi H, Marmouch H, Khochtalì I Fattouma Bourguiba University Hospital department of Endocrinology

\section{Introduction:}

Neurofibromatosis 1 (NF1) or von Recklighausen disease, is an autosomal condition caused by heterozygous mutations of the NF1 gene. Patients with NF-1 are at an approximately fourfold higher risk of developing tumors than the general population. Pheochromocytoma may occur in about $1 \%$ of these patients.

\section{Case report:}

A 24-yr-old woman was admitted to our hospital for further examinations of a $6 \mathrm{~cm}$ right adrenal mass, that was incidentally discovered by abdominal ultrasonography during examinations for asthenia and weight-loss and confirmed by abdominal computed tomographic scans and magnetic resonance imaging.
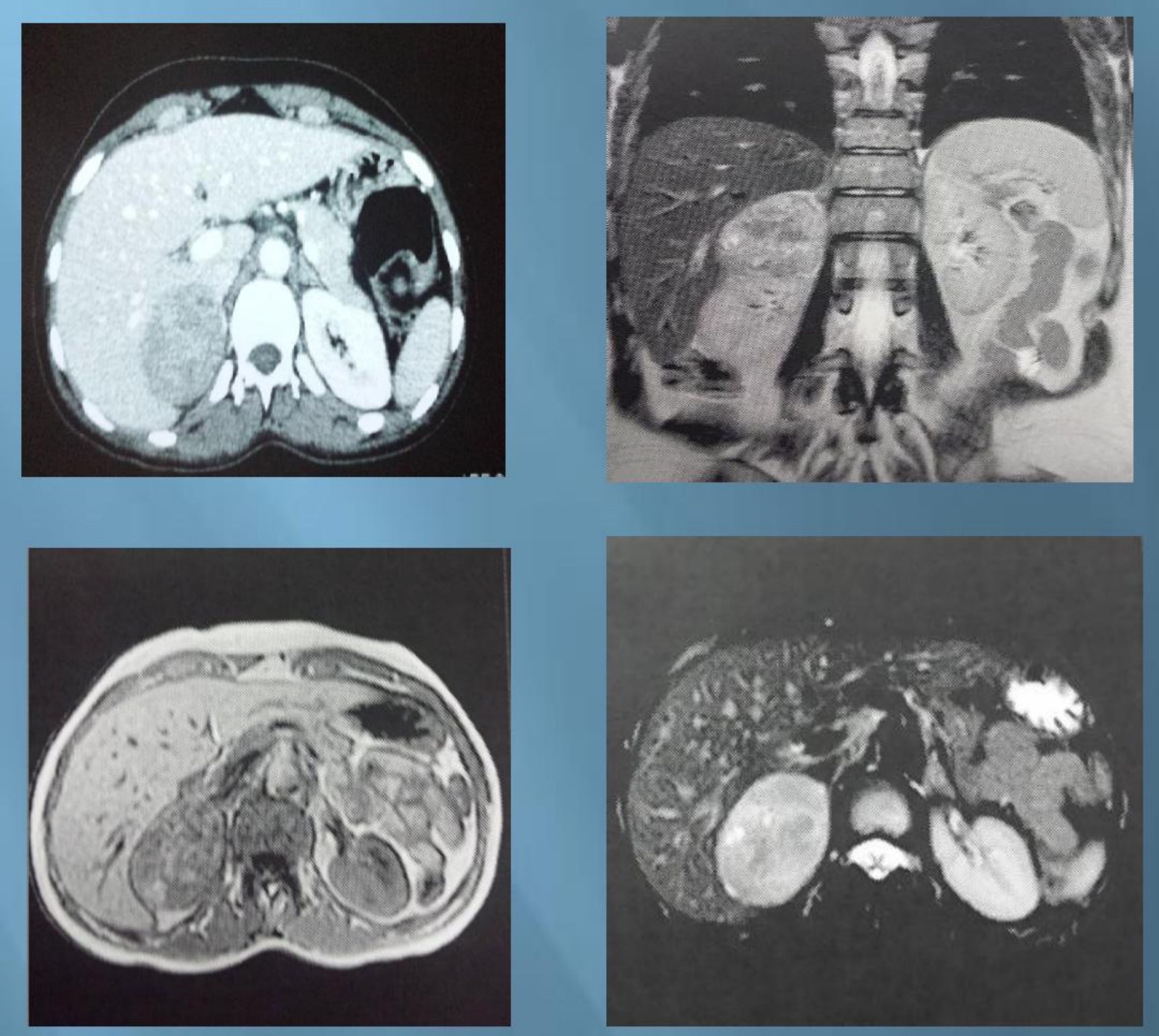

Family medical history revealed that the father had a NF-1. In her past medical history, the patient had many episodes of palpitation, sweating and headache one year before and she was diagnosed to have hypertension one month back. Physical examination revealed signs of NF1.
She had multiple café-au-lait spots on the trunk and extremities and skinfold freckling.

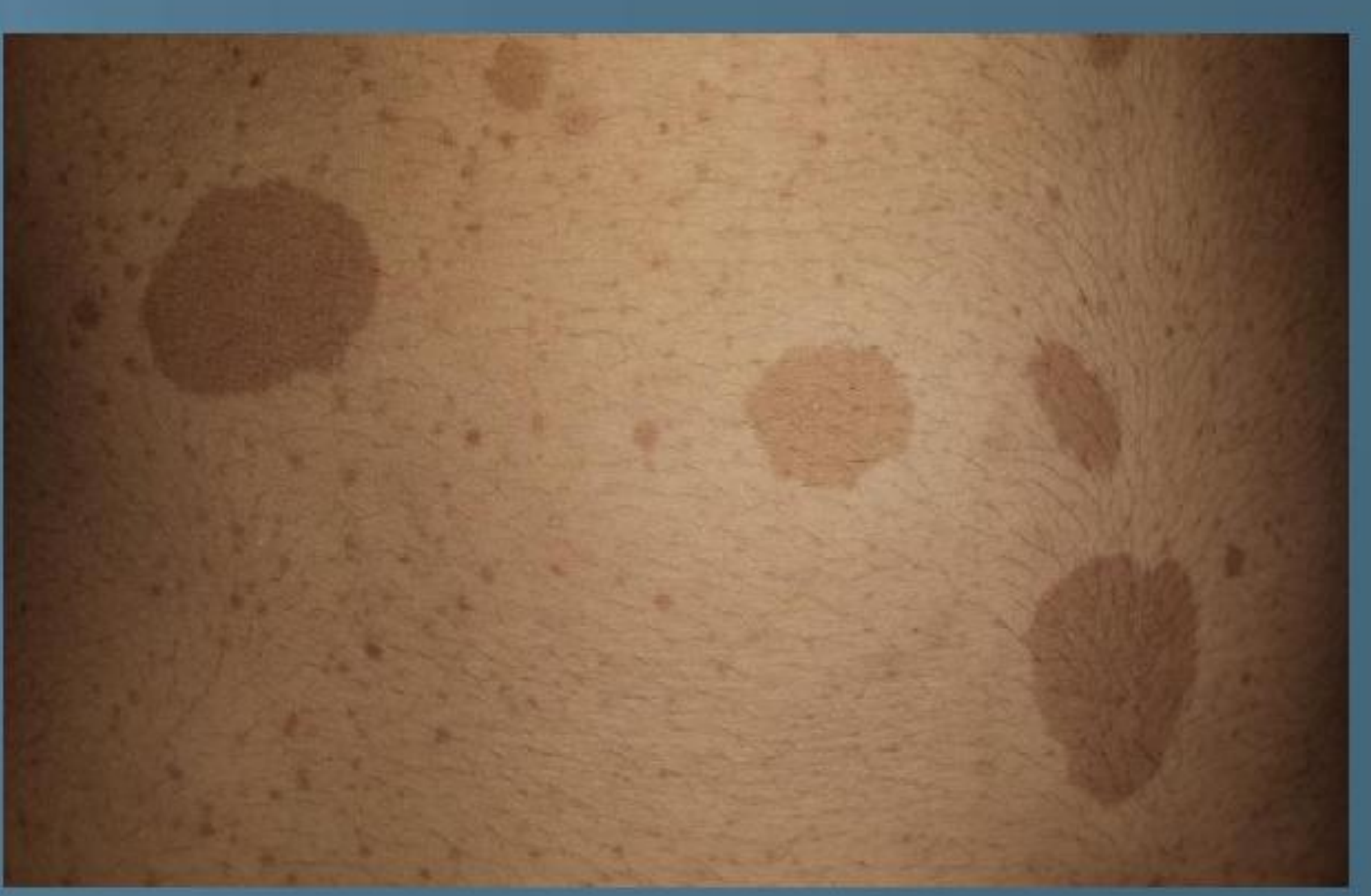

Bilateral opthalmic examination revealed no Lisch nodules. Urinary catecholamines were markedly increased. The treatment with $\beta$-blockers and alpha-blockers kept the patient asymptomatic. Right suprarenalectomy was successfully preformed and the anatomopathological examination of the surgical sample confirmed the diagnosis of pheochromocytoma.

\section{Discussion:}

We report a patient of unilateral pheochromocytoma in the background of neurofibromatosis type 1. NF1 is due to mutation of neurofibromin gene on chromosome 17[1]. NF1 is characterized by cutaneous pigmentary abnormalities and neoplastic growth of neural crestderived cells. In 1910, Suzuki for the first time described the association between pheochromocytoma and type I neurofibromatosis[2]. Pheochromocytoma is seen in about $1 \%$ of NF1 patients but the incidence increases to $20-50 \%$ in cases of NF1 with hypertension. A high index of suspicion is required for identification of such rare association. Data from observational studies suggest that all patients with NF1 and hypertension should undergo a biochemical testing for pheochromocytoma.[4]

\section{Conclusion:}

Our case highlights the role of screening for pheochromocytoma in all patients of neurofibromatosis wich deserves attention especially with the presence of hypertension.

\section{Bibliography:}

1. Dluhy RG. Pheochromocytoma-death of an axiom. N Engl J Med 2002;346:1486-8. 2. Suzuki S. Ueber Zwei Tumoren aus Nebennierenmarkgewebe. Berlin Klein Wchnschr 1910;47:1623.

3.Walther MM, Herring J, Enquist E, Keiser HR, Linehan WM. Von Recklinghausen's disease and pheochromocytomas. J Urol 1999;162:1582-6. 4. Bausch B, Borozdin W, Neumann HP; European-American Pheochromocytoma Study G. Clinical and genetic characteristics of patients with neurofibromatosis type 1 and pheochromocytoma. N Engl J Med 2006;354:2729-31. 